\title{
Bakteriyal İnokulant ve Organik Asit Kullanımının Düşük Kuru Maddeli Küçük Balya Mısır Silajlarının Aerobik Stabilite ve Yem Değeri Üzerine Etkisi ${ }^{\#}$
}

\author{
Erdinç Altınçekiç, İsmail Filya* \\ Uludağ Üniversitesi, Ziraat Fakültesi, Zootekni Bölümü1609 Bursa, Türkiye
}

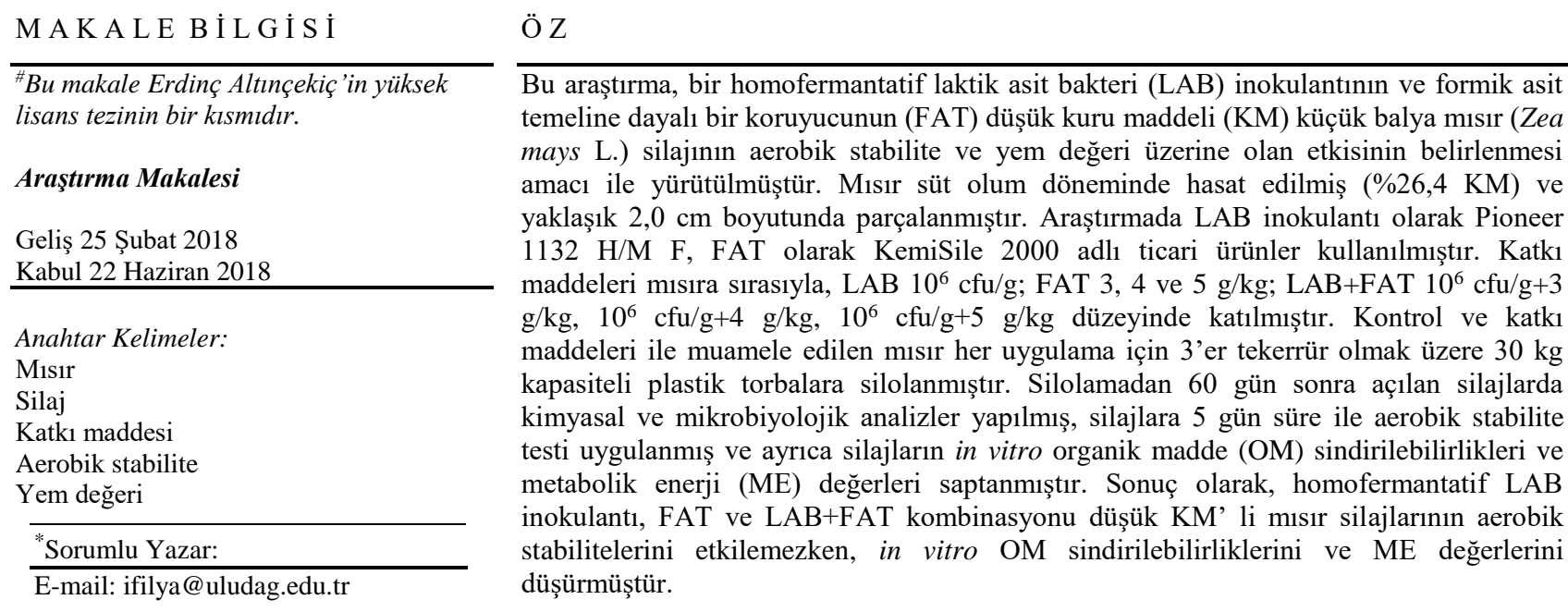

Turkish Journal of Agriculture - Food Science and Technology, 6(7): 887-892, 2018

Effect of Using Bacterial Inoculant and Organic Acid on the Aerobic Stability and Feed Value of Small Bale Maize Silages Containing Low Dry Matter

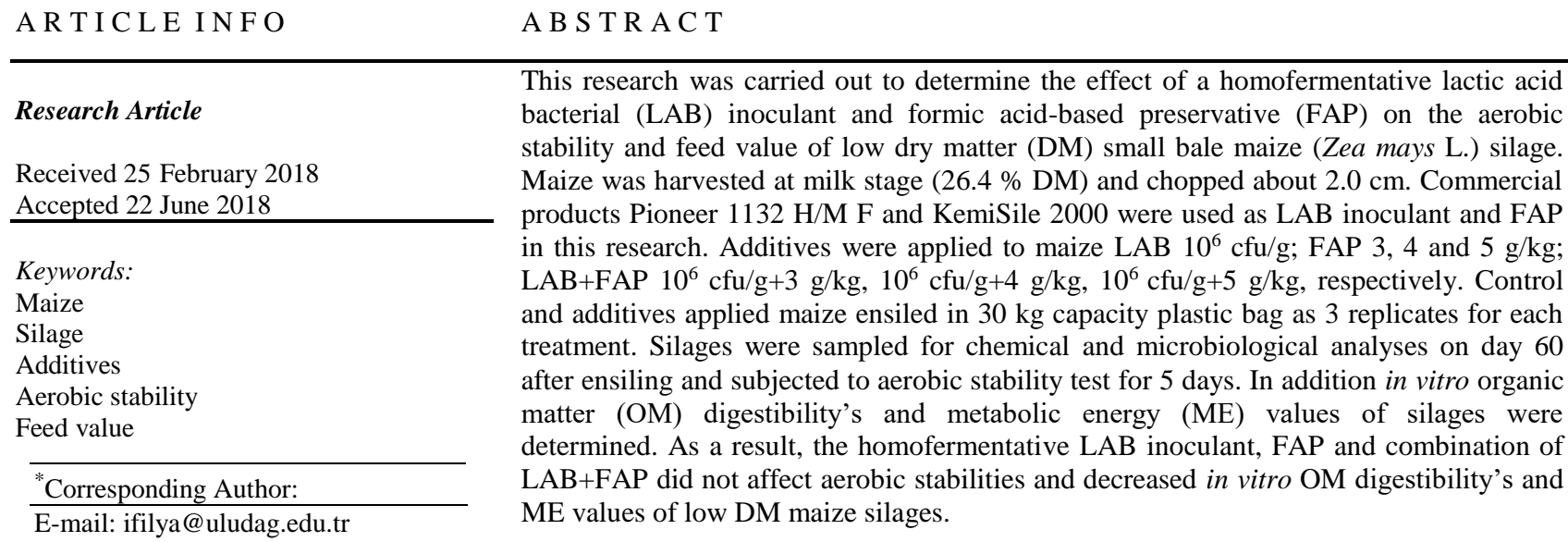




\section{Giriş}

Silaj fermantasyonunda katkı maddeleri kullanımı yaygın bir uygulama olup bu amaçla kullanılan çok sayıda biyolojik ve kimyasal kökenli ürün bulunmaktadır. Söz konusu ürünler genel olarak fermantasyon etkinliği ve aerobik stabiliteyi geliştirmek, hijyenik riskleri en aza indirmek için kullanılırlar.

Silaj fermantasyonunda yaygın olarak kullanılan bakteriyal inokulantlardan homofermantatif laktik asit bakteri (LAB) inokulantları büyük bir hızla laktik asit üreterek ortam $\mathrm{pH}$ 'sını düşürürler. $\mathrm{Bu}$ sayede de silaj fermantayonunu kontrol altına alarak fermantasyon etkinliğini geliştirirler (Weinberg ve Muck, 1996). Nitekim bu konuda yapılan çalışmalarda homofermantatif LAB inokulantlarının fermantasyon etkinliğini geliştirdiği belirlenmiştir (Filya ve Sucu, 2010; Koç ve ark., 2017). Ancak söz konusu inokulantların aerobik stabilite üzerindeki etkileri ise değişken olmuştur. Ranjit ve Kung (2000) homofermantatif LAB inokulantlarının silajların aerobik stabilitesini geliştirdiğini bildirirken, $\mathrm{Hu}$ ve ark. (2009) etkilemediğini, Muck (2004) ise düşürdüğünü bildirmiştir.

Başta tahıl silajları olmak üzere tüm silajlar aerobik bozulmaya karşı hassastırlar (Ashbell ve ark., 2002). Söz konusu silajların aerobik stabilitelerini geliştirmek için kullanılan katkı maddelerinden birisi de kimyasal kökenli katkı maddeleridir. Bu tür ürünler ortamı hızla asitleştirip mikrobiyal büyümeyi önleyerek aerobik stabiliteyi geliştirirler (Woolford, 1984). Nitekim Driehuis ve Van Wikselar (1996) ile Salawu ve ark. (2001) formik asidin silajların aerobik stabilitesini geliştirdiğini belirlemişlerdir. Bununla birlikte formik asit temeline dayalı bir koruyucu (FAT) ile yapılan çalışmaların bazılarında aerobik stabilitenin artarken (Filya ve Sucu, 2007a,b) bazılarında ise etkilenmediği (özellikle $2 \mathrm{~g} / \mathrm{kg}$ ve altındaki dozlarda) görülmüştür (Filya ve ark., 2004, 2005).

Gerek homofermantatif LAB inokulantları gerekse organik asitlerin silajların yem değeri üzerine olan etkilerinin araştırıldığı çalışma sayısı hala sınırlı olup yapılan çalışmalar ağırlıklı olarak silajların kuru madde $(\mathrm{KM})$, organik madde (OM) ve nötr deterjanda çözünmeyen lif (NDF) parçalana bilirliği ve/veya sindirile bilirliği üzerine olmuştur. Meeske ve ark. (1993) homofermantatif LAB inokulantlarının silajların in vitro OM parçalana bilirliğini etkilemediğini belirlemiştir. Homofermantatif LAB inokulantlarının silajların yem değeri üzerine yapılan çalışmalarda da benzer sonuçlar alınmış olup, söz konusu inokulantlar silajların in situ KM ve OM parçalana bilirliklerini (Filya, 2003) in vitro $\mathrm{KM}$ sindirile bilirliğini (Filya ve ark., 2007), in vitro KM, OM ve NDF sindirile bilirliği ile metabolik enerji (ME) değerini (Filya ve Sucu, 2010) etkilememiştir.

Diğer yandan formik asidin silajların yem değeri üzerine olan etkileri konusunda yapılmış araştırma sayısı çok sınırlı olup Polan ve ark. (1998) ile Filya ve Sucu (2007b) formik asidin silajların in vitro OM sindirile bilirliğini etkilemediğini belirlemişlerdir.

Bu çalışmada, bir homofermantatif LAB inokulantı ve bir FAT kullanılmıştır. Söz konusu katkı maddelerinin ayrı ayrı ve çeşitli düzeylerdeki kombinasyonlarının (LAB+FAT) özellikle düşük KM'li küçük plastik balya mısır silajlarının aerobik stabilitesi ve yem değeri üzerine olan etkilerinin incelenmesi amaçlanmıştır.

\section{Materyal ve Yöntem}

Silaj Materyali ve Silolar

Araştırmanın silaj materyalini Uludağ Üniversitesi Ziraat Fakültesi (UÜZF) Tarımsal Araştırma ve Uygulama Merkezi'nde yetiştirilen C-955 misır (Zea mays L.) çeşidi oluşturmuştur. Silo olarak ise yaklaşı 30 $\mathrm{kg}$ kapasiteli $60 \times 90 \mathrm{~cm}$ boyutlarında ve $0.3 \mathrm{~mm}$ kalınlığında özel hava geçirmez plastik torbalar kullanılmıştır.

\section{Katkı Maddeleri}

Araştırmada katkı maddesi olarak bir homofermantatif LAB inokulant1 (Pioneer 1132 H/M F, Pioneer ${ }^{\circledR}$, Hi Bred International Inc., Des Moines, IA, USA) ve FAT (KemiSile 2000, KemiSile ${ }^{\circledR}$, Kemira Oyj - Industrial Chemicals, Finland) kullanılmıştır. Katkı maddesinin ticari kullanım bilgilerine göre inokulant Lactobacillus plantarum ve Enterococcus faecium içermekte olup Rogosa agar üzerinde sayılan mikroorganizma sayısı 1.25 $\times 10^{11} \mathrm{cfu} / \mathrm{g}$ 'dır. Diğer FAT ise $\% 55$ formik asit, $\% 24$ amonyum format, $\% 5$ propiyonik asit, $\% 1$ benzoik asit, $\% 1$ benzoik asit esteri ve \%14 su içermektedir.

\section{Silajların Hazırlanması}

Araştırmada kullanılan mısır süt olum döneminde (\%26,4 KM) hasat edilmiş ve silaj makinesinde yaklaşık $2,0 \mathrm{~cm}$ boyutunda parçalanmıştır. Parçalanan materyale LAB inokulantı $1 \times 10^{6} \mathrm{cfu} / \mathrm{g}$ düzeyinde, FAT ise $3,0,4,0$ ve $5,0 \mathrm{~g} / \mathrm{kg}$ düzeyinde katılmıştır. Ayrıca her iki katkı maddesinin kombinasyonu da kullanılmıştır. Araştırmada $720 \mathrm{~kg}$ misır kullanılmış ve her birisi 30'ar kg olan 24 küçük plastik balya mısır silajı yapılmıştır. Araştırmada kontrol, 1 LAB inokulantı uygulaması, 3 FAT uygulamas1 $(3,0,4,0$ ve $5,0 \mathrm{~g} / \mathrm{kg})$ ve $3 \mathrm{LAB}+$ FAT uygulamas1 şeklinde toplam 8 uygulama ve her uygulama için 3 tekerrür öngörülmüştür. İnokulantın uygulaması sırasında $0,24 \mathrm{~g}$ inokulant tartılarak çeşme suyunda çözülmüş ve temiz bir plastik örtü üzerine yayılan $30 \mathrm{~kg}$ misıra homojen bir şekilde püskürtülerek iyice karıştırılırken, FAT de her seferinde $30 \mathrm{~kg}$ misira $3,0,4,0$ ve $5,0 \mathrm{~kg} / \mathrm{kg}$ düzeyinde (sırasıyla 90, 120 ve $150 \mathrm{~g}$ ) homojen bir şekilde püskürtülerek karıştırılmıştır. Ayrıca her iki katkı maddesinin de aynı oranlarda birlikte yer aldığı ve aynı şekilde hazırlandığı kombinasyonlara da yer verilmiştir.

Kimyasal ve Mikrobiyolojik Analizler

Taze ve 60 günlük silolama dönemi sonunda açılan misır silajlarının KM, amonyak azotu $\left(\mathrm{NH}_{3}-\mathrm{N}\right)$, ham protein (HP) ve ham kül (HK) içerikleri AOAC (1990)'a göre, suda çözünebilir karbonhidrat (SÇK) içerikleri fenol sülfürik asit yöntemine göre (Dubois ve ark., 1956), NDF, ADF ve ADL içerikleri Van Soest ve ark. (1991)'na göre belirlenirken, hemisellüloz ve sellüloz içerikleri hesap yolu ile (hemisellüloz $=$ NDF-ADF, sellüloz $=$ ADFADL) belirlenmiştir. Diğer yandan silajlarda aerobik stabilitelerinin belirlenmesinde Ashbell ve ark. (1991) tarafından geliştirilen yöntem kullanılmıştır. Silajların maya ve küf içeriği ise pH 4.0'e kadar asitleştirilmiş malt ekstrakt agar (Difco, Detroit, MI, USA) kullanılarak, $30^{\circ} \mathrm{C}$ 'de 3 gün süre ile inkübe edilmesiyle belirlenmiştir.

\section{In Vitro Gaz Üretim Özellikleri}

Silajların in vitro koşullardaki gaz üretimi, ME değeri ve $\mathrm{OM}$ sindirilebilirliği in vitro gaz üretim tekniği ile belirlenmiştir (Menke ve Steingass, 1988). Yöntemde 
öncelikle silajların, rumen sıvısı ve yapay tükrük çözeltisi karışımındaki 3, 6, 12, 24, 48, 72 ve 96 saatlik inkübasyonlar sonucundaki gaz hacimleri ölçülmüştür. Daha sonra bu veriler Ørskov ve McDonald (1979) tarafından geliştirilen matematik modele göre hesaplanarak silajların gaz üretim değerleri belirlenmiştir. Diğer yandan silajların ME içerikleri ve in vitro OM sindirilebilirlikleri Menke ve ark. (1979) tarafından kaba yemler için bildirilen eşitliklerden yararlanılarak hesaplanmıştır.

\section{Istatistik Analizler}

Araştırmadan elde edilen verilerin istatistiki olarak değerlendirilmesinde varyans analizi (SAS, 1988), ortalamalar arası farklılıkların önem seviyelerinin kontrol edilmesinde ise Duncan çoklu karşılaştırma testinden yararlanılmıştır (Snedecor ve Cochran, 1980). Maya ve küf analizinde her seferinde üç tekerrür karıştırılıp bir örnek olarak analiz edildiği için istatistiki değerlendirme yapılamamıştır.

\section{Bulgular}

Taze ve silolanmış mısıra ait kimyasal analiz sonuçları Tablo 1'de verilmiştir. Silajlarda en düşük pH kontrol ve LAB inokulantı kullanılan grupta belirlenmiş, inokulant uygulaması FAT ve LAB+FAT uygulamasına göre silajların pH'sını daha fazla düşürmüştür $(\mathrm{P}<0,05)$. Bununla birlikte FAT ve FAT $+\mathrm{LAB}$ uygulamaları arasında ise herhangi bir farklılığa rastlanmamıştır $(\mathrm{P}>0,05)$. Diğer yandan araştırmada kullanılan tüm katkı maddesi ve kombinasyonları silajların $\mathrm{NH}_{3}-\mathrm{N}$ konsantrasyonlarını kontrol grubuna göre düşürmüştür
$(\mathrm{P}<0,05)$. Ancak FAT ve LAB+FAT kullanılan gruplardaki düşüş kontrol ve LAB inokulantı kullanılan gruplara göre daha yüksek olmuştur $(\mathrm{P}<0,05)$

Altmış günlük silolama dönemi sonunda açılan silajlara uygulanan 5 günlük aerobik stabilite testine ait bulgular Tablo 2'de verilmiştir. Gerek LAB gerekse FAT ve $\mathrm{LAB}+\mathrm{FAT}$ uygulamaları misır silajlarının hava ile temas ettiği bu 5 günlük süre boyunca $\mathrm{pH}$ ve $\mathrm{CO}_{2}$ üretimlerini etkilememiştir. Her ne kadar LAB inokulantı uygulaması kontrole göre sayısal olarak silajların $\mathrm{CO}_{2}$ üretimini artırırken, FAT uygulaması düşürse de söz konusu artış ve düşüşler önemsiz bulunmuştur ( $\mathrm{P}>0,05)$. Ayrıca katkı maddesi uygulanan tüm gruplardaki maya ve küf (LAB+ $5 \mathrm{~g} / \mathrm{kg}$ FAT hariç) miktarı sayısal olarak kontrol grubundan daha düşük bulunmuştur.

Taze misır ve silajlara ait hücre duvarı bileşenleri Tablo 3'de verilmiştir. Tüm katkı maddesi uygulamaları kontrol grubuna göre silajların NDF içeriklerini artırırken, FAT ve LAB+FAT kullanılan gruplardaki artışlar önemli olmuştur $(\mathrm{P}<0,05)$. Diğer yandan yalnızca LAB uygulaması kontrole göre silajların ADF içeriklerini düşürürken $\quad(\mathrm{P}>0,05)$, diğer tüm katkı maddesi uygulamaları artırmış ancak sadece $\mathrm{LAB}+3 \mathrm{~g} / \mathrm{kg}$ FAT ve $\mathrm{LAB}+4 \mathrm{~g} / \mathrm{kg}$ FAT uygulanan gruplar ile kontrol ve LAB uygulanan grup arasındaki farklılıklar önemli bulunmuştur $(\mathrm{P}<0,05)$. Araştırmada kullanılan katkı maddeleri ve kombinasyonları silajların ADL içeriklerini etkilememiştir. Bununla birlikte yalnızca $\mathrm{LAB}+4 \mathrm{~g} / \mathrm{kg}$ FAT ve $\mathrm{LAB}+5 \mathrm{~g} / \mathrm{kg}$ FAT uygulanan gruplar kontrol grubuna göre silajların hemisellüloz içeriklerini artırırken $(\mathrm{P}<0,05)$, katkı maddesi uygulamaları kontrol grubu ile karşılaştırıldığında silajların sellüloz içeriğini etkilememiştir.

Tablo 1 Taze mısır ve mısır silajlarına ait kimyasal analiz sonuçları $\left(\overline{\mathrm{X}} \pm \mathrm{S}_{\overline{\mathrm{X}}}\right)$

Table 1 Results of chemical analysis of fresh maize and silages $\left(\bar{X} \pm S_{\bar{x}}\right)$

\begin{tabular}{l|cccccc}
\multicolumn{1}{c|}{ Uygulama } & $\mathrm{KM}$ & $\mathrm{pH}$ & $\mathrm{SÇK}$ & $\mathrm{NH}_{3}-\mathrm{N}$ & $\mathrm{HP}$ & $\mathrm{HK}$ \\
\hline Taze misir & $26,4 \pm 0,11$ & $5,83 \pm 0,13$ & $15,6 \pm 0,08$ & - & $7,2 \pm 0,17$ & $6,0 \pm 0,12$ \\
Kontrol & $25,7 \pm 0,11^{\mathrm{a}}$ & $3,68 \pm 0,01^{\mathrm{bc}}$ & $1,7 \pm 0,03^{\mathrm{f}}$ & $15,6 \pm 0,72^{\mathrm{a}}$ & $7,1 \pm 0,16^{\mathrm{cd}}$ & $7,5 \pm 0,08^{\mathrm{abc}}$ \\
LAB & $25,6 \pm 0,27^{\mathrm{a}}$ & $3,65 \pm 0,00^{\mathrm{c}}$ & $2,2 \pm 0,06^{\mathrm{ef}}$ & $13,8 \pm 0,77^{\mathrm{b}}$ & $7,1 \pm 0,09^{\mathrm{bcd}}$ & $7,0 \pm 0,20^{\mathrm{d}}$ \\
$3 \mathrm{~g} / \mathrm{kg} \mathrm{FAT}$ & $24,5 \pm 0,17^{\mathrm{a}}$ & $3,76 \pm 0,01^{\mathrm{ab}}$ & $4,0 \pm 0,00^{\mathrm{cd}}$ & $10,1 \pm 0,15^{\mathrm{cd}}$ & $6,7 \pm 0,21^{\mathrm{d}}$ & $7,3 \pm 0,07^{\mathrm{bcd}}$ \\
$4 \mathrm{~g} / \mathrm{kg} \mathrm{FAT}$ & $25,0 \pm 0,14^{\mathrm{a}}$ & $3,77 \pm 0,04^{\mathrm{ab}}$ & $3,7 \pm 0,02^{\mathrm{d}}$ & $7,0 \pm 0,44^{\mathrm{f}}$ & $8,2 \pm 0,21^{\mathrm{a}}$ & $7,8 \pm 0,03^{\mathrm{a}}$ \\
$5 \mathrm{~g} / \mathrm{kg} \mathrm{FAT}$ & $24,6 \pm 0,09^{\mathrm{a}}$ & $3,85 \pm 0,06^{\mathrm{a}}$ & $7,5 \pm 0,55^{\mathrm{b}}$ & $3,7 \pm 0,14^{\mathrm{g}}$ & $7,2 \pm 0,07^{\mathrm{bcd}}$ & $7,7 \pm 0,06^{\mathrm{ab}}$ \\
LAB+3 g/kg FAT & $23,5 \pm 0,31^{\mathrm{a}}$ & $3,82 \pm 0,01^{\mathrm{a}}$ & $2,8 \pm 0,15^{\mathrm{e}}$ & $11,1 \pm 0,67^{\mathrm{c}}$ & $7,4 \pm 0,05^{\mathrm{bc}}$ & $7,4 \pm 0,05^{\mathrm{bcd}}$ \\
LAB+4 g/kg FAT & $23,9 \pm 0,19^{\mathrm{a}}$ & $3,82 \pm 0,03^{\mathrm{a}}$ & $4,5 \pm 0,23^{\mathrm{c}}$ & $9,3 \pm 0,21^{\mathrm{de}}$ & $7,0 \pm 0,27^{\mathrm{cd}}$ & $7,6 \pm 0,28^{\mathrm{abc}}$ \\
LAB+5 g/kg FAT & $24,4 \pm 0,18^{\mathrm{a}}$ & $3,80 \pm 0,01^{\mathrm{a}}$ & $8,8 \pm 0,28^{\mathrm{a}}$ & $8,0 \pm 0,03^{\mathrm{ef}}$ & $7,7 \pm 0,14^{\mathrm{ab}}$ & $7,2 \pm 0,03^{\mathrm{cd}}$ \\
\hline
\end{tabular}

$\mathrm{KM}$, kuru madde; SÇK, suda çözünebilir karbonhidrat; $\mathrm{NH}_{3}-\mathrm{N}$, amonyak azotu; HP, ham protein; $\mathrm{HK}$, ham kül, LAB, laktik asit bakteri inokulantı; FAT, formik asit temeline dayalı koruyucu, $\mathrm{pH}, \mathrm{KM}$ ve $\mathrm{NH}_{3}-\mathrm{N}$ dişındaki parametreler $\mathrm{KM}$ ' de \%, $\mathrm{NH}_{3}-\mathrm{N}$ ise toplam $\mathrm{N}$ ' in \%'si olarak verilmiştir, Aynı sütunda farklı harfler ile gösterilen ortalamalar arasındaki farklılıklar önemlidir $(\mathrm{P}<0,05)$.

Tablo 2 Mısır silajlarına ait aerobik stabilite test sonuçları $\left(\overline{\mathrm{X}} \pm \mathrm{S}_{\overline{\mathrm{X}}}\right)$

Table 2 Results of aerobic stability of maize silages $\left(\bar{X} \pm S_{\bar{x}}\right)$

\begin{tabular}{l|cccc}
\multicolumn{1}{c}{ Uygulama } & $\mathrm{pH}$ & $\mathrm{CO}_{2}(\mathrm{~g} / \mathrm{kg} \mathrm{KM})$ & Maya* $^{*} \log$ cfu/g KM$)$ & Küf* $(\log$ cfu/g KM $)$ \\
\hline Kontrol & $5,3 \pm 0,29^{\mathrm{a}}$ & $119,3 \pm 25,74^{\mathrm{a}}$ & 8,0 & 7,8 \\
$\mathrm{LAB}$ & $5,1 \pm 0,58^{\mathrm{a}}$ & $145,8 \pm 27,29^{\mathrm{a}}$ & 7,2 & 7,0 \\
$3 \mathrm{~g} / \mathrm{kg} \mathrm{FAT}$ & $4,4 \pm 0,42^{\mathrm{a}}$ & $68,4 \pm 19,44^{\mathrm{a}}$ & 4,6 & 7,1 \\
$4 \mathrm{~g} / \mathrm{kg} \mathrm{FAT}$ & $4,0+0,10^{\mathrm{a}}$ & $83,2 \pm 39,25^{\mathrm{a}}$ & 6,6 & 7,3 \\
$5 \mathrm{~g} / \mathrm{kg} \mathrm{FAT}$ & $4,2 \pm 0,25^{\mathrm{a}}$ & $78,9 \pm 37,55^{\mathrm{a}}$ & 6,5 & 7,6 \\
$\mathrm{LAB+3g/kg} \mathrm{FAT}$ & $4,1 \pm 0,15^{\mathrm{a}}$ & $92,3 \pm 21,73^{\mathrm{a}}$ & 4,6 & 7,2 \\
LAB+4g/kg FAT & $4,8 \pm 0,48^{\mathrm{a}}$ & $111,6 \pm 40,58^{\mathrm{a}}$ & 7,2 & 7,5 \\
LAB+5g/kg FAT & $4,9 \pm 0,49^{\mathrm{a}}$ & $141,4 \pm 32,59^{\mathrm{a}}$ & 7,7 & 7,9 \\
\hline
\end{tabular}

$\mathrm{CO}_{2}$, karbondioksit; KM, kuru madde; log cfu, logaritma koloniform ünite; LAB, laktik asit bakteri inokulantı; FAT, formik asit temeline dayalı koruyucu, Aynı sütunda farklı harfler ile gösterilen ortalamalar arasındaki farklılıklar önemlidir $(\mathrm{P}<0,05)$. *Maya ve küf analizleri her seferinde bir örnek üzerinde yapıldığı için istatistik analiz yapılamamıştır. 
Tablo 3 Taze mısır ve mısır silajlarının hücre duvarı bileşenleri $\left(\overline{\mathrm{X}} \pm \mathrm{S}_{\overline{\mathrm{x}}}, \% \mathrm{KM}\right)$

Table 3 Cell wall components of fresh maize and silages $\left(\bar{X} \pm S_{\bar{x}}, D M \%\right)$

\begin{tabular}{l|ccccc}
\multicolumn{1}{c}{ Uygulama } & NDF & ADF & ADL & Hemisellüloz* & Sellüloz* \\
\hline Taze misir & $62,7 \pm 0,69$ & $29,7 \pm 0,56$ & $2,2 \pm 0,35$ & $33,0 \pm 0,23$ & $27,5 \pm 0,58$ \\
Kontrol & $56,8 \pm 0,81^{\mathrm{d}}$ & $34,1 \pm 0,23^{\mathrm{bc}}$ & $4,0 \pm 0,40^{\mathrm{a}}$ & $22,7 \pm 0,87^{\mathrm{b}}$ & $30,1 \pm 0,35^{\mathrm{ab}}$ \\
LAB & $57,5 \pm 0,29^{\mathrm{cd}}$ & $33,6 \pm 0,92^{\mathrm{c}}$ & $5,6 \pm 0,29^{\mathrm{a}}$ & $24,0 \pm 1,27^{\mathrm{ab}}$ & $28,0 \pm 1,04^{\mathrm{b}}$ \\
3 g/kg FAT & $61,2 \pm 0,87^{\mathrm{bc}}$ & $36,0 \pm 0,81^{\mathrm{abc}}$ & $6,9 \pm 1,10^{\mathrm{a}}$ & $25,2 \pm 0,29^{\mathrm{ab}}$ & $29,1 \pm 0,46^{\mathrm{ab}}$ \\
4 g/kg FAT & $62,0 \pm 0,40^{\mathrm{ab}}$ & $36,3 \pm 1,04^{\mathrm{abc}}$ & $5,1 \pm 0,87^{\mathrm{a}}$ & $25,7 \pm 0,92^{\mathrm{ab}}$ & $31,2 \pm 1,16^{\mathrm{ab}}$ \\
5 g/kg FAT & $62,7 \pm 0,69^{\mathrm{ab}}$ & $37,8 \pm 0,58^{\mathrm{ab}}$ & $6,2 \pm 1,27^{\mathrm{a}}$ & $24,9 \pm 0,92^{\mathrm{ab}}$ & $31,5 \pm 1,10^{\mathrm{ab}}$ \\
LAB+3 g/kg FAT & $63,8 \pm 0,35^{\mathrm{ab}}$ & $38,7 \pm 0,35^{\mathrm{a}}$ & $5,9 \pm 0,46^{\mathrm{a}}$ & $25,0 \pm 0,69^{\mathrm{ab}}$ & $32,9 \pm 0,58^{\mathrm{a}}$ \\
LAB+4 g/kg FAT & $65,8 \pm 0,75^{\mathrm{a}}$ & $38,6 \pm 0,29^{\mathrm{a}}$ & $6,7 \pm 1,91^{\mathrm{a}}$ & $27,2 \pm 1,98^{\mathrm{a}}$ & $31,8 \pm 1,68^{\mathrm{ab}}$ \\
LAB+5 g/kg FAT & $62,5 \pm 0,46^{\mathrm{ab}}$ & $35,3 \pm 0,35^{\mathrm{abc}}$ & $4,8 \pm 0,52^{\mathrm{a}}$ & $27,2 \pm 0,81^{\mathrm{a}}$ & $30,5 \pm 0,46^{\mathrm{ab}}$ \\
\hline
\end{tabular}

KM, kuru madde; NDF, nötr deterjanda çözünmeyen lif; ADF, asit deterjanda çözünmeyen lif; ADL, asit deterjanda çözünmeyen lignin; LAB, laktik asit bakteri inokulantı; FAT, formik asit temeline dayalı koruyucu. *Hesap yolu ile belirlenmiștir. Hemisellüloz $=$ NDF-ADF, Sellüloz $=$ ADF-ADL Aynı sütunda farklı harfler ile gösterilen ortalamalar arasındaki farklılıklar önemlidir $(\mathrm{P}<0,05)$.

Tablo 4 Misır silajlarının in vitro gaz üretimleri $\left(\overline{\mathrm{X}} \pm \mathrm{S}_{\overline{\mathrm{X}}}, \mathrm{ml}\right)$ Table 4 In vitro gas productions of maize silages $\left(\bar{X} \pm S_{\bar{x}}, m l\right)$

\begin{tabular}{|c|c|c|c|c|c|c|c|}
\hline \multirow{2}{*}{ Uygulama } & \multicolumn{7}{|c|}{ İnkübasyon zamanları (saat) } \\
\hline & 3 & 6 & 12 & 24 & 48 & 72 & 96 \\
\hline Kontrol & $20,8 \pm 0,68^{a}$ & $26,2 \pm 0,83^{\mathrm{a}}$ & $37,0 \pm 1,21^{\mathrm{a}}$ & $47,7 \pm 5,20^{\mathrm{a}}$ & $55,5 \pm 1,89^{a}$ & $63,0 \pm 3,73^{\mathrm{a}}$ & $65,2 \pm 3,70^{\mathrm{a}}$ \\
\hline LAB & $15,5 \pm 0,24^{\mathrm{c}}$ & $19,2 \pm 0,36^{\mathrm{d}}$ & $24,5 \pm 0,36^{\mathrm{cd}}$ & $30,7 \pm 0,44^{\mathrm{c}}$ & $35,8 \pm 0,54^{\mathrm{b}}$ & $37,3 \pm 0,81^{\mathrm{b}}$ & $38,8 \pm 0,81^{\mathrm{b}}$ \\
\hline $3 \mathrm{~g} / \mathrm{kg}$ FAT & $17,8 \pm 0,14^{\mathrm{b}}$ & $23,2 \pm 0,14^{\mathrm{b}}$ & $30,3 \pm 1,18^{b}$ & $36,8 \pm 1,88^{\mathrm{b}}$ & $44,0 \pm 2,24^{\mathrm{b}}$ & $46,8 \pm 2,72^{b}$ & $48,8 \pm 2,72^{\mathrm{b}}$ \\
\hline $4 \mathrm{~g} / \mathrm{kg}$ FAT & $17,0 \pm 0,47^{\mathrm{b}}$ & $21,8 \pm 0,85^{\mathrm{bc}}$ & $28,8 \pm 1,11^{\mathrm{bc}}$ & $37,0 \pm 1,61^{\mathrm{bc}}$ & $42,0 \pm 2,06^{\mathrm{b}}$ & $42,4 \pm 1,59^{b}$ & $46,3 \pm 2,32^{b}$ \\
\hline $5 \mathrm{~g} / \mathrm{kg}$ FAT & $15,0 \pm 0,00^{\mathrm{c}}$ & $19,7 \pm 0,27^{\mathrm{cd}}$ & $27,3 \pm 0,54^{\mathrm{bcd}}$ & $34,3 \pm 0,33^{\mathrm{bc}}$ & $41,3 \pm 0,27^{\mathrm{b}}$ & $44,2 \pm 0,36^{\mathrm{b}}$ & $45,8 \pm 0,41^{b}$ \\
\hline $\mathrm{LAB}+3 \mathrm{~g} / \mathrm{kg}$ FAT & $15,3 \pm 0,14^{\mathrm{c}}$ & $19,8 \pm 0,24^{\mathrm{cd}}$ & $27,2 \pm 0,47^{\mathrm{bcd}}$ & $35,0 \pm 0,50^{\mathrm{bc}}$ & $42,5 \pm 0,95^{\mathrm{b}}$ & $46,0 \pm 1,18^{b}$ & $48,2 \pm 1,06^{\mathrm{b}}$ \\
\hline $\mathrm{LAB}+4 \mathrm{~g} / \mathrm{kg}$ FAT & $13,5 \pm 0,24^{\mathrm{d}}$ & $17,3 \pm 0,94^{\mathrm{d}}$ & $23,0 \pm 1,66^{\mathrm{d}}$ & $29,8 \pm 2,75^{\mathrm{c}}$ & $37,3 \pm 3,07^{\mathrm{b}}$ & $41,3 \pm 4,13^{b}$ & $42,7 \pm 4,01^{\mathrm{b}}$ \\
\hline $\mathrm{LAB}+5 \mathrm{~g} / \mathrm{kg}$ FAT & $15,5 \pm 0,24^{\mathrm{c}}$ & $19,3 \pm 0,94^{\mathrm{cd}}$ & $25,8 \pm 1,67^{\text {bcd }}$ & $32,7 \pm 2,89^{b c}$ & $38,7 \pm 3,19^{\mathrm{b}}$ & $41,2 \pm 3,65^{\mathrm{b}}$ & $42,5 \pm 3,42^{\mathrm{b}}$ \\
\hline
\end{tabular}

LAB, laktik asit bakteri inokulantı; FAT, formik asit temeline dayalı koruyucu, Aynı sütunda farklı harfler ile gösterilen ortalamalar arasındaki farkl11ıklar önemlidir $(\mathrm{P}<0,05)$.

Tablo 5 Misir silajlarının metabolik enerji ve in vitro organik madde sindirilebilirlikleri $\left(\overline{\mathrm{X}} \pm \mathrm{S}_{\overline{\mathrm{x}}}\right)$ Table 5 Metabolic energy and in vitro organic matter digestibilities of maize silages $\left(\bar{X} \pm S_{\bar{x}}\right)$

\begin{tabular}{l|cc}
\hline \multicolumn{1}{c|}{ Uygulama } & ME (Kcal/kg) & In vitro OMS (\%) \\
\hline Kontrol & $2172 \pm 169,0^{\mathrm{a}}$ & $57,6 \pm 4,87^{\mathrm{a}}$ \\
LAB & $1620 \pm 13,2^{\mathrm{b}}$ & $42,7 \pm 0,36^{\mathrm{b}}$ \\
$3 \mathrm{~g} / \mathrm{kg} \mathrm{FAT}$ & $1815 \pm 58,4^{\mathrm{b}}$ & $48,1 \pm 1,77^{\mathrm{b}}$ \\
$4 \mathrm{~g} / \mathrm{kg}$ FAT & $1840+49,3^{\mathrm{b}}$ & $48,3 \pm 1,55^{\mathrm{b}}$ \\
$5 \mathrm{~g} / \mathrm{kg} \mathrm{FAT}$ & $1740 \pm 10,9^{\mathrm{b}}$ & $45,9 \pm 0,23^{\mathrm{b}}$ \\
LAB+3 g/kg FAT & $1764 \pm 16,1^{\mathrm{b}}$ & $46,5 \pm 0,42^{\mathrm{b}}$ \\
LAB+4 g/kg FAT & $1590 \pm 87,9^{\mathrm{b}}$ & $41,9 \pm 2,33^{\mathrm{b}}$ \\
LAB+5 g/kg FAT & $1692 \pm 95,1^{\mathrm{b}}$ & $44,5 \pm 2,47^{\mathrm{b}}$ \\
\hline
\end{tabular}

ME, metabolik enerji; OMS, organik madde sindirilebilirliği; LAB, laktik asit bakteri inokulantı; FAT, formik asit temeline dayalı koruyucu. Aynı sütunda farklı harfler ile gösterilen ortalamalar arasındaki farklılıklar önemlidir $(\mathrm{P}<0,05)$.

Silajların 3-96 saat arasında belirli zamanlarda ölçülen gaz üretimleri Tablo 4'de verilmiştir. Tüm katkı maddesi uygulamaları daha ilk saatlerden itibaren silajların in vitro gaz üretimlerini kontrol grubuna göre önemli düzeyde düşürmüş ve bu trend 96. saate kadar devam etmiştir $(\mathrm{P}<0,05)$. Diğer yandan LAB, FAT ve LAB+FAT uygulamaları arasında inkübasyonun ilk saatlerinde bazı farklılıklar gözlense de özellikle 24. saatten sonra herhangi bir farklılı̆ga rastlanmamıştır $(\mathrm{P}>0,05)$

Silajlara ait ME ve in vitro $\mathrm{OM}$ sindirilebilirlikleri Tablo 5'de verilmiştir. Araştırmadaki tüm katkı maddesi uygulamaları kontrol grubuna göre silajların $\mathrm{ME}$ ve in vitro $\mathrm{OM}$ sindirilebilirliklerini düşürmüştür $(\mathrm{P}<0,05)$. Ayrıca söz konusu parametreler açısından katkı maddeleri ve kombinasyonları arasında da herhangi bir farklılık görülmemiştir $(\mathrm{P}>0,05)$.

\section{Tartışma}

Altmış günlük silolama dönemi sonunda açılan, gerek kontrol gerekse katkı maddesi kullanılmış tüm silajların pH'ları düşmüștür. Mısır bitkisinin silaj fermantasyonu için yeterli $\mathrm{SÇK}$ içeriğine sahip olması $\mathrm{pH}$ düşüşü üzerinde etkili olmuştur. Özellikle LAB'nin SÇK'ları kullanarak asidik bir ortam oluşturması $\mathrm{pH}$ düşüşünü hızlandırmıştır. $\mathrm{Bu}$ durum özellikle LAB inokulantı kullanılan grupta açıkça görülmüştür. Nitekim Weinberg ve ark. (2002) buğday ve misır, Filya ve Sucu (2010) buğday, misır ve sorgumda kullanılan homofermantatif LAB inokulantlarının hızlı bir fermantasyona yol açarak laktik asit üretim hızını artırdığını ve bunun da silajların pH'larını düşürdüğünü belirlemişlerdir. Bunun yanı sıra araştırıcılar söz konusu inokulantların silajlardaki protein parçalanmasını da azaltarak silajların $\mathrm{NH}_{3}-\mathrm{N}$ konsantrasyonlarının da düştüğünü bildirmişlerdir. Diğer 
yandan araştırmadaki tüm katkı maddesi uygulamaları kontrol grubuna göre silajların $\mathrm{NH}_{3}-\mathrm{N}$ konsantrasyonlarını düşürmüştür $(\mathrm{P}<0,05)$. Özellikle FAT uygulamasının silajlardaki fermantasyonu sınırlandırması sonucu FAT ve FAT+LAB kullanılan gruplardaki $\mathrm{NH}_{3}-\mathrm{N}$ konsantrasyonları, hem kontrol hem de yalnızca LAB kullanılan gruplardakinden daha düşük olmuştur $(\mathrm{P}<0,05)$. Benzer şekilde Rooke ve ark. (1988) ve Winters ve ark. (2001) formik asidin İngiliz ve İtalyan çimi silajlarındaki $\mathrm{NH}_{3}-\mathrm{N}$ konsantrasyonunu düşürdüğünü belirlerken, Filya ve Sucu (2007a,b) FAT uygulamasının buğday, misır ve sorgum silajlarında proteolisisi önleyerek silajların $\mathrm{NH}_{3}-\mathrm{N}$ konsantrasyonunu düşürdüğünü belirlemişlerdir.

Altmış günlük silolama dönemi sonunda silajlara 5 gün süre ile aerobik stabilite testi uygulanmıştır. Silajların doğrudan hava ile etkileşime birakıldığ 1 bu periyod sonucunda kontrol ve katkı maddesi uygulanan silajlar arasında $\mathrm{pH}$ ve $\mathrm{CO}_{2}$ üretimi bakımından herhangi bir farklılığa rastlanmamıştır $(\mathrm{P}>0,05)$. Dolayısıyla gerek $\mathrm{LAB}$ ve FAT gerekse $\mathrm{LAB}+\mathrm{FAT}$ kombinasyonu düşük KM'li mısır silajlarının aerobik stabilitesini etkilememiştir. Özellikle araştırmada kullanılan mısırın düşük bir KM içeriğine sahip olması ve bunun sonucunda silajlarda görülen yüksek su aktivitesi burada önemli rol oynamıştır. Ranjit ve Kung (2000) mısır, Filya (2003) buğday, misır ve sorgumda kullanılan homofermantatif LAB inokulantlarının silajların aerobik stabilitelerini düşürdügünü belirlerken, Filya ve ark. (2000) söz konusu inokulantların soldurulmamış buğday, Hu ve ark. (2009) ise mısır silajlarının aerobik stabilitelerini etkilemediğini belirlemişlerdir. Weinberg ve ark. (2002) silajların hava ile temas ettikleri bu aerobik dönemde silajlardaki laktatların bazı mayalar tarafindan tüketilmesi sonucu ortamdaki maya sayısının artış gösterdiğini ve bunun da $\mathrm{CO}_{2}$ üretimini artırarak silajların aerobik stabilitesini düşürdüğünü bildirmişlerdir. Araştırmada kullanılan homofermantatif LAB inokulantı kontrol grubuna göre silajların $\mathrm{CO}_{2}$ üretimini sayısal olarak artırmış ancak bu artış önemli bulunmamıştır $(\mathrm{P}>0,05)$. Diğer yandan FAT uygulaması silo içerisinde asidik bir ortam yaratarak fermantasyonu sınırlandırmış ve antimikrobiyal özelliği sayesinde de maya ve küf gelişimini baskı altına almıştır. Bunun sonucunda FAT katılan silajlardaki $\mathrm{CO}_{2}$ üretimi hem kontrol hem de LAB+FAT katılan gruplardan daha düşük olmuş ancak bu düşüş önemli bulunmamıştır $(\mathrm{P}>0,05)$. Bu konu ile ilgili olarak buğday, mısır ve sorgum silajları ile yapılan çok sayıdaki çalışmamada da farklı sonuçlar alınmıştır. Bazı çalışmalarda FAT silajlardaki maya ve küf sayısını azaltıp, $\mathrm{CO}_{2}$ üretimini düşürerek silajların aerobik stabilitesini artırırken (Filya ve Sucu, 2007a,b) bazı çalışmalarda ise (özellikle $2 \mathrm{~g} / \mathrm{kg}$ ve altındaki dozlarda) etkilememiştir (Filya ve ark., 2004, 2005).

Araştırmada kullanılan LAB inokulantı kontrol grubu ile karşılaştırıldığında mısır silajlarının hücre duvarı bileşenlerini etkilememiştir. Diğer yandan FAT uygulaması kontrol grubuna göre silajların NDF içeriğini artırırken $(\mathrm{P}<0,05), \mathrm{ADF}, \mathrm{ADL}$, hemisellüloz ve sellüloz (3g/kg FAT hariç) içeriğini de sayısal olarak artırmış ancak söz konusu bu artışlar önemli bulunmamıştır (P>0,05). Ranjit ve Kung (2000) ile Filya ve Sucu (2010) homofermantatif LAB' nin mısır silajlarının hücre duvarı bileşenlerini etkilemediğini bildirmişlerdir. Bununla birlikte Filya ve Sucu (2007b) $2 \mathrm{~g} / \mathrm{kg}$ düzeyindeki FAT uygulamasının buğday silajlarının hücre duvarı bileşenlerini etkilemediğini ancak $4 \mathrm{~g} / \mathrm{kg}$ düzeyindeki uygulamanın ise silajların NDF, ADF, ADL ve sellüloz içeriklerini düşürürken, hemisellüloz içeriğini artırdığını belirlemişlerdir. Diğer yandan araştırmada kullanılan tüm katkı maddesi ve kombinasyonları mısır silajlarının daha ilk saatlerden itibaren in vitro gaz üretimlerini düşürmüş ve bu düşüş inkübasyon döneminin sonuna kadar devam etmiştir. Özellikle 48. saatten sonra katkı maddeleri arasında görülen farklıklar da ortadan kalkmış ve gerek LAB ve FAT gerekse LAB+FAT katılan tüm gruplar ile kontrol grubu arasındaki farklılıklar önemli düzeyde bulunmuştur $(\mathrm{P}<0,05)$. Silajların in vitro gaz üretimlerindeki bu düşüş, silajların $\mathrm{ME}$ ve in vitro $\mathrm{OM}$ sindirilebilirliğine de yansımıştır. Buna bağlı olarak katkı maddesi kullanılan tüm grupların $\mathrm{ME}$ ve in vitro $\mathrm{OM}$ sindirilebilirlikleri kontrol grubuna göre önemli düzeyde düşüş göstermiştir $(\mathrm{P}<0,05)$. Bu sonuçlar $\mathrm{LAB}$ ve FAT uygulamalarının özellikle rumen içi koşullar üzerinde olumsuz bir etkiye yol açmış olabileceğini düşündürmektedir. Homofermantatif LAB inokulantlarının mısır silajlarının yem değeri üzerine etkileri ile ilgili olarak yapılan çalışmalarda Polat ve ark. (2005) in situ OM parçalanabilirliğinin, Filya ve Sucu (2010) in vitro KM, OM ve NDF sindirilebilirliği ile ME değerinin etkilenmediğini belirlemişlerdir. Diğer yandan Kennedy (1990) homofermantatif LAB inokulantlarının silajların OM sindirilebilirliğini düşürdüğünü bildirirken, Polan ve ark. (1998) ile Filya ve Sucu (2007b) formik asitin silajların in vitro $\mathrm{OM}$ sindirilebilirliğini etkilemediğini bildirmişlerdir.

Araştırma sonucunda gerek homofermantatif LAB gerekse FAT kullanımının düşük KM'li mısır silajlarının aerobik stabilitesini etkilemediği ve in vitro $\mathrm{OM}$ sindirilebilirliği ile ME değerini düşürdüğü belirlenmiştir. Dolayısıyla araştırmada kullanılan gerek biyolojik gerekse organik asit temelli katkı maddeleri düşük KM'li misır silajlarının gerek aerobik stabilitelerini gerekse yem değerini geliştirmede yetersiz kalmışlardır. Araştırmada kullanılan FAT her ne kadar silajlardaki aerobik bozulmanın başlıca sorumlusu olan maya sayısını azaltıp $\mathrm{CO}_{2}$ üretimlerini düşürerek silajların aerobik stabilitesini geliştirse de bu önemsiz düzeyde kalmıştır ( $\mathrm{P}>0,05)$. Burada mısırın düşük KM'ye, dolayısıyla yüksek bir su aktivitesine sahip olması etkili olmuştur. Diğer yandan her iki katkı maddesi de rumen mikroorganizmalarının faaliyetini olumsuz yönde etkileyerek daha az in vitro gaz üretmelerine yol açmış ve bunun sonucunda silajların in vitro $\mathrm{OM}$ sindirilebilirliği ve $\mathrm{ME}$ değeri düşmüştür. $\mathrm{Bu}$ çalışmada da tartışıldığı gibi katkı maddelerinin silajların yem değeri üzerindeki etkileri çok faklı olup, olumlu, olumsuz ve nötr sonuçlar söz konusudur. $\mathrm{Bu}$ konu üzerinde uzun yıllardır çalışılmakta ve farklı sonuçlar alınmaya devam edilmektedir. Nitekim Filya ve ark. (2007) ile Muck ve ark. (2007) kullandıkları çok sayıdaki homofermantatif ve heterofermantatif LAB inokulantının iki farklı KM içeriğine sahip yonca silajlarının in vitro gaz üretimi, uçucu yağ asitleri kompozisyonu ve yem değerini etkilemediğini belirlemişler ve özellikle olumlu sonuçlar alınan çalışmalarda görülen artışların sindirile bilirlik veya başka faktörlerden de kaynaklanabileceğini 
bildirmişlerdir. Dolayısıyla bu konu ile ilgili olarak daha ayrıntılı değerlendirmeler yapabilmek için çok daha geniş bir bilgi birikimine ve bilimsel çalışmaya gereksinim duyulduğu çok açıktır.

\section{Kaynaklar}

AOAC. 1990. Official methods of analysis. Vol 1., 15th ed. Association of Official Analytical Chemists, Arlington, VA, USA.

Ashbell G, Weinberg ZG, Azrieli A, Hen Y, Horev B. 1991. A simple system to study the aerobic deterioration of silages. Canadian Agricultural Engineering. 33: 171-175.

Ashbell G, Weinberg ZG, Hen Y, Filya I. 2002. The effects of temperature on the aerobic stability of wheat and corn silages. Journal of Industrial Microbiology \& Biotechnology. 28: 261-263.

Driehuis F, Van Wikselaar PG. 1996. Effects of formic, acetic or propionic acid to maize silage and low dry matter grass silage on the microbial flora and aerobic stability. Proceedings of the 11th International Silage Conference, Aberystwyth, Wales, pp. 256-257.

Dubois M, Giles KA, Hamilton JK, Rebes PA, Smith F. 1956. Colorimetric method for determination of sugars and related substances. Analytical Chemistry. 28: 350-356.

Filya I, Ashbell G, Hen Y, Weinberg ZG. 2000. The effect of bacterial inoculants on the fermentation and aerobic stability of whole crop wheat silage. Animal Feed Science and Technology. 88: 39-46.

Filya I. 2003. The effect of Lactobacillus buchneri, with or without homofermentative lactic acid bacteria, on the fermentation, aerobic stability, and ruminal degradability of wheat, sorghum, and maize silages. Journal of Applied Microbiology. 95: 1080-1086.

Filya İ, Sucu E, Hanoğlu H. 2004. Biyolojik katkı maddeleri kullanılarak yapılan küçük plastik balya mısır silajlarını kalite özellikleri, yem değeri ve kuzu besisinde kullanımı üzerine bir araştırma. Tarım Bilimleri Dergisi, 10(2): 158-162.

Filya İ, Sucu E, Canbolat Ö. 2005. Silaj yapımında ve süt ineklerinin beslenmesinde organik asit kullanımı üzerinde araştırmalar. 1. Formik asit temeline dayalı bir koruyucunun mısır silajlarının kalite özellikleri üzerine etkisi. GAP IV. Tarım Kongresi. Şanlıurfa. s. 1719-1722.

Filya I, Muck RE, Contreras-Govea FE. 2007. Inoculant effects on alfalfa silage: fermentation products and nutritive value. Journal of Dairy Science. 90: 5108-5114.

Filya İ, Sucu E. 2007a. The effect of bacterial inoculants and a chemical preservative on the fermentation and aerobic stability of whole-crop cereal silages. Asian-Australian Journal Animal Science. 20(3): 378-384.

Filya I, Sucu E. 2007b. Effect of a chemical preservative on fermentation, aerobic stability and nutritive value of wholecrop wheat silage. Journal of Applied Animal Research. 32: 133-138.

Filya İ, Sucu E. 2010. The effects of lactic acid bacteria on the fermentation, aerobic stability and nutritive value of mazie silage. Grass \& Forage Science. 65: 446-455.

$\mathrm{Hu}$ W, Schmidt RJ, McDonell EE, Klingerman CM, Kung Jr L. 2009. The effect of Lactobacillus buchneri 40788 or Lactobacillus plantarum MTD-1 on the fermentation and aerobic stability of corn silages ensiled at two dry matter contetnts. Journal of Dairy Science. 92: 3907-3914.

Kennedy SJ. 1990. An evaluation of three bacterial inoculants and formic acid as additive for harvest grass. Grass \& Forage Science. 45: 281-288.

Koc F, Ozturk Aksoy S, Agma Okur A, Celikyurt G, Korucu D, Ozduven ML. 2017. Effect of pre-fermented juice, Lactobacillus plantarum and Lactobacillus buchneri on the fermentation charecteristics and aerobic stability of high dry matter alfalfa bale silage. The Journal of Animal \& Plant Sciences. 27(5): 1426-1431.
Meeske R, Assbell G, Weinberg ZG, Kipnis T. 1993. Ensiling forage sorghum at two stage of maturity with the addition of lactic adcid bacterial inoculants. Animal Feed Science and Technology. 43: 165-175.

Menke KH, Raab L, Salewski A, Steingess H, Fritz D, Schneider W. 1979. The estimation of the digestibility and metabolisable energy content of ruminant feedinstuffs from the gas production when they are incubated with rumen liquor. The Journal of Agricultural Science. 93: 217-222.

Menke KH, Steingass H. 1988. Estimation of energetic feed value obtained from chemical analysis and in vitro gas production using rumen fluid. Animal Research and Development. 28: 7-55.

Muck RE. 2004. Effects of corn silage inoculants on aerobic stability. American Society of Agricultural and Biological Engineers. 4: 1011-1016.

Muck RE, Filya I, Contreras-Govea FE. 2007. Inoculant effects on alfalfa silage: In vitro gas and volatile fatty acid production. Journal of Dairy Science. 90: 5115-5125.

Ørskov ER, McDonald I. 1979. The estimation of protein degradabillity in trhe rumen from incubation measurements weighted according to the rate of passage. The Journal of Agricultural Science. 92: 499-503.

Polan CE, Stieve DE, Garrett JL. 1998. Protein preservation and ruminal degradation of ensiled forage treated with heat, formic acid, ammonia, or microbial inoculant. Journal of Dairy Science. 81: 765-776.

Polat C, Koç F, Özdüven ML. 2005. Mısır silajında laktik asit bakteri ve laktik asit bakteri+enzim karışımı inokulantların fermanasyon ve toklularda ham besin maddelerinin sindirilme dereceleri üzerine etkileri. Trakya Üniversitesi Ziraat Fakültesi Dergisi. 2(1): 13-22.

Ranjit NK, Kung Jr L. 2000. The effect of Lactobacillus buchneri, Lactobacillus plantarum, or a chemical preservative on the fermentaion and aerobic stability of corn silage. Journal of Dairy Science. 83: 526-535.

Rooke JA, Maya FM, Arnold JA, Armstrong DG. 1988. The chemical composition and nutritive value of grass silages prepared with no additive or with the application of additives containing either Lactobacillus plantarum or formic acid. Grass \& Forage Science. 43: 87-95.

SAS. 1988. SAS ${ }^{\circledR}$ User's Guide: Statistics, Version 6. SAS Institute, Cary, NC, USA.

Salawu MB, Warren EH, Adesogan AT. 2001. Fermentation characteristics, aerobic stability and ruminal degradation of ensiled pea/wheat bi-crop forages treated with two microbial inoculants, formic acid or quebracho tannins. Journal of the Science of Food and Agriculture. 81: 1263-1268.

Snedecor GW, Cochran WG. 1980. Statistical Methods. 6th ed. Iowa State Univ. press, Ames, IA, USA.

Van Soest PH, Robertson JB, Lewis BA. 1991. Methods for dietary fiber, neutral detergent fiber, and nonstarch polysaccharides in relation to animal nutrition. Journal of Dairy Science. 74: 3583-3597.

Weinberg ZG, Muck RE. 1996. New trends and opportunities in the development and use of inoculants for silage. FEMS Microbiology Reviews. 19: 53-68.

Weinberg ZG, Ashbell G, Hen Y, Azrieli A, Szakacs G, Filya I. 2002. Ensiling whole-crop wheat and corn in large containers with Lactobacillus plantarum and Lactobacillus buchneri. Journal of Industrial Microbiology and Biotechnology. 28: 7-11.

Winters AI, Fycan R, Jones R. 2001. Effect of formic acid and a bacterial inoculant on the amino acid composition of grass silage and on animal performance. Grass \& Forage Science. 56: $181-192$.

Woolford MK. 1984. The silage fermentation. Microbiology series, 14. Marcel Dekker Inc., New York, USA. 